\title{
A Case report on unusual cause of young ischemic Cerebrovascular Accident: a rare complication of honey Bee stings
}

\author{
Varuni $K^{1}$, Sivansuthan $S^{1}$, Joseph Piratheepan $G^{1}$, Gajanthan $R^{1}$ \\ ${ }^{1}$ Teaching Hospital Jaffna. \\ Corresponded Author: Varuni K \\ Email: Ingaranvaruni2012@gmail.com \\ https://orcid.org/0000-0003-1282-6144
}

\begin{abstract}
Honeybee stings usuallywon'trequire hospitalization. The clinical features of Bee stings can be from local reactions such as pain, wheal, flare, edema, swelling to systemic anaphylactic reactions and infrequent major complications reported from different studies include rhabdomyolysis, acute renal failure, acute pulmonary edema, disseminated intravascular coagulation, stroke, encephalopathy and very rarely cerebral hemorrhage. $(1,2)$ Stroke following bee sting can be due to toxins itself, following anaphylactic shock or pain induced catecholamines surge. Here we report a case on ischemic Cerebrovascular accident following multiple Bee stings complicated with anaphylactic shock.
\end{abstract}

(Keywords: Stroke, ARF, bee sting, cerebrovascular accident)

\section{Introduction}

Bee belongs to the order of Hymenoptera. Bee and wasp stings are worldwide common problem due to venomous stings. Despite Bee sting usually causes local and systemic allergic reactions due to its venom, it can rarely cause neurological complications such as Cerebrovascular accident. Other reported neurological complications of venomous honey bee included seizure, aphasia, dysarthria, apraxia, ataxia, and coma. There are only handful cases reported in the world literature on stroke following single or multiple wasp or bee stings. $(3,4)$ Here we report, a young ischemic cerebrovascular accident following multiple Bee stings.

\section{Case report}

A 44-year-old businessman, having Bronchial Asthma for 15 years was stung by multiple honey bees in all over the body including face and neck while he tried to collect honey. Initially he developed facial swelling, dizziness and shortness of breath in addition to pain and itching. On arrival to ETU of local hospital within 15 minutes he had blood pressure of 70/30 mmHg, PR 128bpm, SPO2 85\% with oxygen support and diffuse rhonchi. Within few minutes he developed unrecordable blood pressure. Immediately he was given IV 1:10000 $0.5 \mathrm{ml}$ Adrenalin, IV 200mg Hydrocortisone and IV $10 \mathrm{mg}$ Chlorpheniramine with bolus normal saline. He recovered from shock. But he had bilateral rhonchi with SPO2 92\% and it was managed with Salbutamol nebulization and oxygen. Then he was transferred to Jaffna teaching hospital within 30 minutes following resuscitations. On admission to emergency unit his BP was $180 / 100 \mathrm{mmHg}$, PR $110 \mathrm{bpm}$ and GCS 14/15. He was kept in continuous monitoring. BP was going up to $240 / 120 \mathrm{mmHg}$. We started hydralazine infusion. As blood pressure was still high GTN also started in addition to hydralazine.

We noticed later that he was unable to move the left side limbs. A non contrast CT brain done 10 hours later from admission showed hypodense area in right side posterior cerebral artery territory including occipital lobe, thalamus, external capsules and basal ganglia with mild cerebral edema with mass effect and midline shift $(5 \mathrm{~mm})$ on left side(figure1). Then he was managed as ischemic CVA. He was commenced on Aspirin $300 \mathrm{mg}$ and Atorvastatin $40 \mathrm{mg}$ daily.

Next day his conscious level was unchanged. On $3^{\text {rd }}$ day it was reduced to GCS $11 / 15$ with unequal reactive pupil. Then repeat NCCT brain was done on same day, which showed same infarcted area with worsening cerebral edema, mass effect and midline shift $(7 \mathrm{~mm})$ and hemorrhagic transformation (figure 2). He gradually gained normal GCS with improvement in limb power.

We evaluated the possible etiology for young CVA including ECG, ECHO, CXR, abdominal ultra sound scan, carotid and vertebral Doppler scan and $\mathrm{CT}$ angiogram and risk factors assessment, which 
were not revealing any clue. As all the invetigations were normal we concluded that his CVA was due to toxins and vasogenic substances released from bee sting venom causing intense vasospasm and high blood pressure. Other possible contributory factors were pain induced catecholamines surge causing high blood pressure and hypotension due to anaphylactic shock. He was discharged after rehabilitation on day 12 of hospital admission. Antiplatelet was restarted. On discharge he had muscle power of $3 / 5$ with ability of swallowing of solid. One month later he was able to move and walk with support.

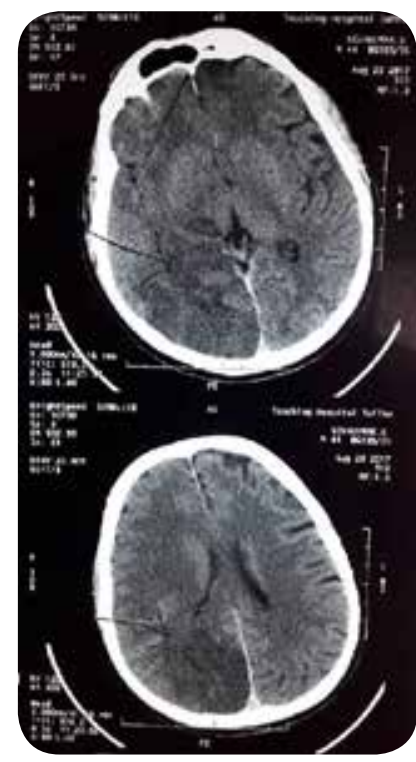

Figure 1. NCCT brain

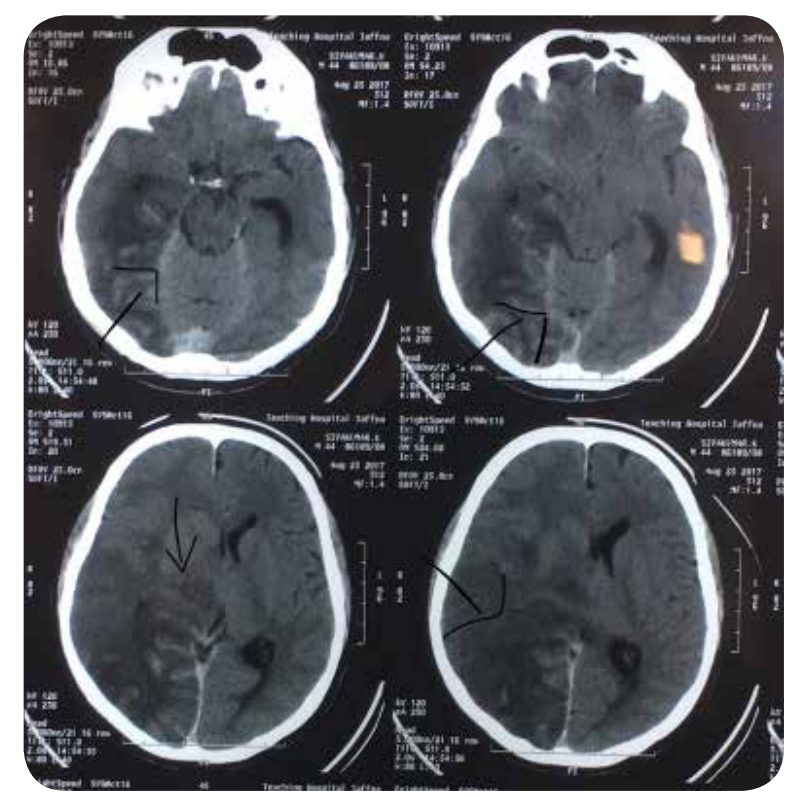

Figure 2. 2nd NCCT brain - hemorrhagic transformation

\section{Discussion}

There are few case reports in stroke following Bee sting. Wasp or bee stings usually won't cause neurological manifestations. But rarely they can precipitate ischemic cerebrovascular accident, hemorrhagic cerebrovascular accident, or cerebral venous thrombosis due to its direct effect. It can occur due to single or multiple sting. As they usually live in colonies, multiple stings are common than single sting. (2)

There are multiple theories for development of stroke following Bee sting. One of the mechanisms is hypoxia and hypotension related to anaphylactic shock.(4) Others are enhanced platelet aggregations and thrombogenesis from toxic substances released from bee stings, vasoconstriction induced by the inflammatory mediators released from our body and from bee's venom, and vasoconstriction due to severe pain induced catecholamine surge. Those vasogenic inflammatory substances are histamine, serotonin, bradykinin, leukotrienes and thromboxane. Catecholamines can be endogenous vasoconstrictors such as dopamine and adrenalin or exogenous adrenalin given for anaphylaxis.(5) In case of head and neck sting, there is a chance to get intense stimulations of the superior cervical ganglion causing constriction of blood vessels. $(4,6)$

In this case we can attribute Anaphylactic shock induced hypotension as a cause for stroke. Hypotension is associated with infarction in border zone - watershed areas located between posterior and middle cerebral artery or anterior and middle cerebral artery because that areas are more vulnerable to hypoxia . $(7,9)$ Hypotension usually cause bilateral and multi infarction. When a watershed infarct is seen unilaterally, this is usually due to hemodynamic narrowing of a proximal artery without intact collateral vessels and with or without superimposed hypotension.(7) So, this is unlikely to be a cause for stroke in this scenario as it involves one arterial territory. Watershed infarction is characteristically associated with focal seizures. $(8,9)$ Here, the time of onset of stroke also did not relate to time of hypotension. After anaphylactic shock he was moving his limbs for few hours. But it can't exclude reliably. If stroke is due to hypotensive episode, poor perfusion can cause renal impairment and ischemic hepatitis. (10) 
Toxic mediators also can cause infarction with variable time and even multiple infarction. $(2,3)$ Here we can attribute that sting induced release of toxic mediators and pain induced release of catecholamines caused intense vasoconstrictions and high BP complicated with ischemic CVA. There is no definitive diagnostic test to differentiate these two causes. There are possible contributions from adrenalin injection used for anaphylaxis in this patient as well. (11)

\section{Conclusions}

Bee sting can rarely cause ischemic CVA either due to direct effect of toxic substances and vasogenic and thrombogenic substances released from bee sting or indirectly pain induced catecholamines surge and anaphylactic shock.

\section{References}

1. Murat G, Handan A, Ali KE. Acute ischemic stroke and severe multiorgan dysfunction due to bee sting. turk J Emerg Med.2016 sep;16(3):126-128. [Pub Med]

2. Jain J, Banait S, Srivastava AK, Lodhe $R$. Stroke intracerebral multiple infarcts: Rare neurological presentation of honey bee bite .Ann Indian Acad Neurol.2012 Apr;15(2):163-6. doi: 10.4103/09722327.95008.[PubMed]

3. Rajendiran C, Puvanalingam A, Thangam D. Stroke after multiple BEE sting.Japi.2012 feb;60:44-46.[PubMed]

4. Wani M, Saleem S, Verma S, Yousuf I, Asimi R, Daga RA, Shah I, Aejaz. Multiple cerebral infarctions with severe multiorgan dysfunction following multiple wasp stings. Ann Indian Acad Neurol. 2014 Jan;17(1):125-7...[Pub Med]

5. Riggs J.E, Ketonen L.M, Wymer J.P, Barbano R.L, Valanne L.K, Bodensteiner J.B. Acute and delayed cerebral infarction after wasp sting anaphylaxis. Clin Neuropharmacol. 1994;17:384-388. [PubMed]

6. Moein P, Zand R.Cerebral Infarction as a Rare Complication of Wasp Sting.J Vasc Interv Neurol. 2017 Jun;9(4):13-16. [PubMed]

7. David P. Middle_Posterior Watershed. casemed.case.edu.neurology.2006.

8. Juergenson I, Mazzucco S, Tinazzi M.A typical example of cerebral watershed infarct. Clin Pract. 2011 Nov 18;1(4):e114. [PubMed]

9. Denier C, Masnou P, Yacouba M, et al. Watershed infarctions are more prone than other cortical infarcts to cause early-onset seizures. Arch Neurol. 2010;67:1219-23. [PubMed]

10. JohnPC. Lowblood pressure(hypotension), Causes, Sign, Symptoms, Readings, and Readings. MedicineNet.2016

11. Eric S.S, Sandor E. Hemorrhagic Transformation: A Review of the Rate of Hemorrhage in the Major Clinical Trials f Acute Ischemic Stroke. Front Neurol.2013;4:69. [PubMed] 